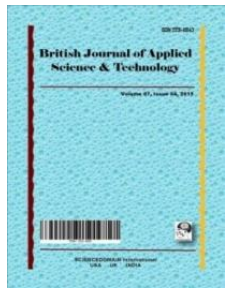

British Journal of Applied Science \& Technology

16(2): 1-10, 2016, Article no.BJAST.23529

ISSN: 2231-0843, NLM ID: 101664541

SCIENCEDOMAIN international

www.sciencedomain.org

\title{
Development of Pedal Operated Honey Extractor
}

\author{
B. O. Akinnuli ${ }^{1}$, O. O. Awopetu ${ }^{1}$, P. P. Ikubanni ${ }^{2^{*}}$ and O. O. Agboola ${ }^{2}$ \\ ${ }^{1}$ Department of Mechanical Engineering, Federal University of Technology, Akure, Ondo State, \\ Nigeria. \\ ${ }^{2}$ Department of Mechanical Engineering, Landmark University, Omu-Aran, Kwara State, Nigeria.
}

Authors' contributions

This work was carried out in collaboration between all authors. Authors BOA and O. O. Awopetu were concerned with the design analysis of the system while authors PPI and O. O. Agboola carried out the production and performance evaluation of the system. Authors PPI and O. O. Agboola wrote the first draft of the manuscript. All authors read and approved the final manuscript.

Article Information

DOI: $10.9734 / B J A S T / 2016 / 23529$

Editor(s):

(1) Manoj Gupta, Department of Mechanical Engineering, NUS, 9 Engineering Drive 1, Singapore 117576,

Singapore.

Reviewers:

(1) Azuddin Mamat, University of Malaya, Malaysia.

(2) Michael Mayokun Odewole, University of Ilorin, Ilorin, Nigeria.

(3) Hao Wang, Northeastern University, Liaoning, P. R. China.

Complete Peer review History: http://sciencedomain.org/review-history/14641

Original Research Article

Received $4^{\text {th }}$ December 2015

Accepted $15^{\text {th }}$ March 2016

Published $16^{\text {th }}$ May 2016

\begin{abstract}
Bees are winged insects that produce honey by their activities with the nectar of flowers. The honey produced is sweet and are finding replacement for sugar nowadays. Honey bees live in hives where the honey combs being formed by the bees are being deposited. Various methods had been exploited in extracting this honey from the honey comb both traditionally and by different designs of extractors from the primitive to a modern one. Although the former design which was locally produced in Nigeria was hand driven which functions quite efficiently, however, there is need for new innovation that involved the introduction of pedaled mechanism. An existing honey extractor design was improved upon with the introduction of pedal mechanism as compared to the hand driven one with the aim of extracting the honey in the most hygienic way with the suitable materials required. The efficiency of the machine was estimated to be 85 per cent, which was compared to the former available designed one of 83 per cent efficiency. The cost analysis for the production of the machine was included in the work which was estimated to be \#48750 (US\$243.75).
\end{abstract}

*Corresponding author: E-mail: p.ikubanni@gmail.com; 
Keywords: Honey; pedaled; extractor; hive; bee; improved; shaft; production; machine; efficiency.

\section{INTRODUCTION}

Bee is a winged, flower-feeding insect which have branched body hairs. They are dependent on pollen as a protein source and on flower nectar or oils as an energy source. Bees are the most important pollinating insects. Their interdependence with green plant makes them an excellent example of the type of symbiosis known as mutualism; in which two parties of an unlike organisms benefits from each other. Bees produce honey from flower nectar. Honey bees and stingless bees are characterized with the ability to hoard large quantities of honey. This is the major reason for beekeepers to make exploit of this opportunity and harvest the honey for human consumption [1]. It is believed that bees are found throughout the world except at the highest altitudes, in Polar Regions, and on some small oceanic islands. This may be due to the fact that the greatest diversity of bee species is found in warm, arid or semi-arid areas especially in the American Southwest and Mexico. Honey bee, the common name for any of several species of highly social bees known for their honey-hoarding behavior and their use as a domesticated species is important in modern agriculture. Honey bees can be easily reared, are adaptable to many climates and to laboratory conditions and have a complex social life. Beekeeping, also known as Apiculture is the management of the colonies of bees for the production of honey and other hive products; and through this practice, different hives had been produced. The early form of collecting honey entailed the destruction of the entire colony when the honey was harvested. The wild hive was crudely broken into, using smoke to suppress the bees; the honey combs were torn out and smashed up along with the eggs, larvae and honey they contained. The liquid honey from the destroyed brood nest was crudely strained through a sieve or basket. Honey mainly consists of sugars and water. Sugars in honey comprises majorly of monosaccharides and oligosaccharides while sugars in it are sweeter and give more energy than artificial sweeteners. They contain several vitamins especially B complex and vitamin $\mathrm{C}$ as well as a lot of minerals [2]. Honey-bee farmers have grown in number to meet the increasing public demand for honey. Honey is a sweet food made by bees using nectar from flowers. Honey has a long history of human consumption and is used in various foods and beverages as a sweetener and flavoring. However, the honey flavors depend on the nectar source.

Honey has numerous health benefits which include the ability to heal wounds, nutritional and therapeutic properties since ancient times. It is good for asthmatic patients and it has been proven to be effective against advanced cases of stomach and bone cancer. Honey is antibacteria, anti-viral and anti-fungal; in which all these properties make it ideal for healing wounds $[2,3]$.

In advanced countries such as United States, Germany, Australia, Italy and so on, series of extractor have been developed and such extractors are tangential, radial, automatic programmable and electrical driven types [4]. However, the honey extracting machines designed by advanced countries for indigenous beginner in the honey industry are of high cost in which indigenous bee keepers will not be able to purchase the types aforementioned. Afogba [5] design and constructed the first indigenous honey extractor in the Federal University of Technology, Akure (FUTA), Nigeria; in which the efficiency of the device was $81.8 \%$ with the capacity of extracting 9 litres of honey per one cycle. The machine is operated manually using chain and sprocket drive as the prime mover and the materials used for the construction were mild steel, high carbon chromium steel and galvanized steel. Abioye [6] introduced gear mechanism in transmitting motion that will help in the honey extraction procedure.

In the former designs, large force is required to overcome the load and its metal basket and it takes long time before out flowing of honey from honey combs due to delay in gathering momentum on time. In addition, operator easily gets tired after few repetition of the extraction process. Although, the production is appreciable but not good enough when it comes to mass production. In order to overcome these short comings in the hand driven extractor, the system was changed to pedal type, to make the required large force available in spinning the metal basket and its load may gather momentum within a short period and the honey available get discharged within a very short period. The extracting process can be repeated as many times as possible without the operator being tired. This work was aimed at designing an improved honey extractor that is pedal driven; fabricate the designed 
improved honey extractor; and evaluate the performance of the produced improved one in comparison with the hand driven type. This will also help the beekeepers to attain better standard of living through improved honey production.

\section{MATERIALS AND METHODS}

The methodology of this research took care of the design analysis of the honey extracting machine, material selection for each component designed, the design calculations of the machine parts, operating description of the system, engineering drawings and required system assembly as well as the estimated production cost.

\subsection{Machine Description and Working Principle}

The developed extractor was made of axial solid shaft carrying the chain driving system on its accommodations, the small sprocket and the bearing topmost part of the shaft. This solid shaft accommodates the hexagonal shaped basket which will accommodate the matured honey comb ready for extraction. The whole mechanism was housed in a galvanized cylindrical container for honey collection and evacuation. The pedal mechanism which gives the machine a drive (rotary motion) consists of a chain mechanism with a sprocket that transmits the motion from the pedal to the shaft that has a big grooved pulley on it, connected to the shaft that invariably drives the basket inside the drum due to the gear mechanism incorporated. The driver gear set in motion the driven gear which invariably set the basket in motion.

The machine operates by the principle of radial motion of the basket inside the drum. The metal basket was loaded with matured honey combs, and the metal basket was spun to rotation by force on the pedals. The rotational effect caused centrifugal force that made the honey to flow out of its comb. As the centrifugal force increases, the rate of honey outflow increases until the combs are empty of their honey. The extracted honey flows down by gravity into the collector for collection and packaging.

\subsection{Design Consideration and Material Selection for Production}

Various design considerations were put into place to be able to have efficient design. The tank body or drum, rotary basket, spinning mechanism and shaft were from stainless steel while the frame, gear, chain, bearing and so on were from mild steel. These decisions were taken to avoid rust which can contaminate the honey and stainless steel used was due to the recommendation for materials preferred for food handling given by Trading Standards agents worldwide.

The materials selected for the design and construction of the machine were majorly the stainless steel and the mild steel. The criteria of selecting these materials are: (i) durability of the material, (ii) strength of the material, (iii) suitability of the material for honey extraction, (iv) availability of the material and (v) the cost of the material.

\subsection{Design of Machine Element}

\subsubsection{Straight bevel gear design}

These gears have a conical pitch surface and straight tapering towards an apex.

Nomenclature;

$Z_{p}=$ Number of teeth of pinion

$Z_{g}=$ Number of teeth on the driven gear

$\alpha=$ Pressure angle of teeth $=20^{\circ}$

$\vartheta_{p}=$ Pitch angle (Pinion) $=\tan ^{-1}\left(Z_{p} / Z_{g}\right)$

$n_{p}=$ Rotational speed of pinion shaft (rev/min)

$d_{p}=$ Pinion pitch circle diameter $(\mathrm{mm})$

$d=$ Driven gear pitch circle diameter $(\mathrm{mm})$ [7]

\subsubsection{Determination of pitch circle diameter}

For the pinion $\mathrm{P}$,

$$
d_{p}=m Z_{p}
$$

Where $m=2.5$ and $Z_{p}=21$ teeth

$$
d_{p}=2.5 \times 21=52.5 \mathrm{~mm}=0.0525 \mathrm{~m}
$$

For the driven bevel bear,

$$
d_{g}=m Z_{g}
$$

Where $m=2.5$ and $Z_{g}=21$ teeth

$$
d_{g}=2.5 \times 21=52.5 \mathrm{~mm}=0.0525 \mathrm{~m}
$$


2.3.3 Determination of pitch angle for bevel gear

The pitch angle is the angle made by the pitch line with the axis of rotation.

$$
\begin{aligned}
& \vartheta_{p}=\tan ^{-1}\left(Z_{p} / Z_{g}\right) \\
& \vartheta_{g}=\tan ^{-1}\left(Z_{g} / Z_{p}\right)
\end{aligned}
$$

Where $Z_{p}=21$ teeth

$$
Z_{g}=21 \text { teeth }
$$

$$
\begin{aligned}
& \vartheta_{p}=\tan ^{-1}(21 / 21)=45^{0} \\
& \vartheta_{g}=\tan ^{-1}(21 / 21)=45^{0}
\end{aligned}
$$

\subsubsection{Specification of the selected chain}

The selected chain of the type 08B-2 ROLON

Pitch, $\mathrm{P}=13 \mathrm{~mm}$

Maximum Roller Diameter, $D_{r}=8 \mathrm{~mm}$

Width between Inner Plate Minimum, $w=5 \mathrm{~mm}$

Pin Body Maximum Diameter, $D_{p}=4 \mathrm{~mm}$

Plate Maximum Depth, $\mathrm{G}=9 \mathrm{~mm}$

Transverse Pitch, $\mathrm{Pt}=16.5 \mathrm{~mm}$

Weight per meter $=0.68 \mathrm{~kg}$

Minimum Breaking Load, $Q=1730 \mathrm{~kg}$

Maximum overall joint, $A_{1}, A_{2}, A_{3}=20 \mathrm{~mm}$

Number of Teeth of Small Sprocket, $Z_{1}=20$

Number of Teeth of Large Sprocket, $Z_{2}=44$

\subsubsection{Determination of small (pinion)} sprockets diameter $(\mathrm{mm})$

$$
d_{1}=\frac{\mathrm{P}}{\sin \frac{180}{Z_{1}}}
$$

Where $\mathrm{P}=$ Pitch of the chain

$$
\begin{aligned}
& Z_{1}=\text { Number of teeth of the small sprocket } \\
& d_{1}=\text { diameter of small sprocket (pinion) [8] } \\
& d_{1}=\frac{13}{\sin \frac{180}{20}}=\frac{13}{\sin 9}=83.11 \mathrm{~mm}
\end{aligned}
$$

\subsubsection{Determination of large sprocket diameter}

$$
d_{2}=\frac{P}{\sin \frac{180}{Z_{2}}}
$$

Where $\mathrm{P}=$ Pitch of the chain

$Z_{2}=$ Number of teeth of the large sprocket

$d_{2}=$ diameter of large sprocket

$$
d_{2}=\frac{13}{\sin \frac{180}{44}}=\frac{13}{\sin 4.091}=182.23 \mathrm{~mm}
$$

\subsubsection{Determination of the service factor, $\mathrm{K}_{5}$}

The service factor, also referred to as selection factor, takes into consideration the condition under which the chain drive will be working.

$$
\mathrm{K}_{\mathrm{s}}=\mathrm{k}_{1} \cdot \mathrm{k}_{2} \cdot \mathrm{k}_{3} \cdot \mathrm{k}_{4} \cdot \mathrm{k}_{5} \cdot \mathrm{k}_{6}
$$

Where:

\section{Local Factor, $\mathrm{k}_{1}=1.0$}

The factor distance regulation, $\mathrm{k}_{2}=1.25$

Factor for centre distance of sprocket, $\mathrm{k}_{3}=1.25$

Factor for portion of the sprocket, $\mathrm{k}_{4}=1.0$

The lubrication factor, $\mathrm{k}_{5}=1.5$

The rating factor, $\mathrm{k}_{6}=1.0$

$$
\begin{aligned}
\mathrm{K}_{\mathrm{s}} & =1.0 \times 1.25 \times 1.25 \times 1.0 \times 1.5 \times 1.0 \\
& =2.34375
\end{aligned}
$$

\subsubsection{Determination of the speed of the pinion}

$$
\frac{z_{2}}{z_{1}}=\frac{n_{1}}{n_{2}}
$$

Where $n_{2}=$ speed of the driver sprocket.

$n_{1}=$ speed of the pinion

$$
n_{1}=\frac{Z_{2} n_{2}}{Z_{1}}=\frac{44 \times 60}{20}=132 \mathrm{rpm}
$$

\subsubsection{Determination of the factor of safety}

The factor of safety $\eta$, is given by

$$
\eta=\frac{Q}{P}
$$

where $P=P_{t}+P_{c}+P_{s}$

$$
P_{t}=
$$

tangential force due to power transmission

$P_{c}=$ centrifugal force

$P_{S}=$ tension due to sagging of chain

$$
\text { Where } P_{s}=K_{s} \cdot W \cdot a
$$

Where $K_{s}=$ coefficient of sag $=6$

$a=$ centre distance $=0.39 \mathrm{~m}$

$W=$ weight per metre of chain $=0.77 \mathrm{kgF}$

Therefore, $P_{s}=6 \times 0.77 \times 0.39=1.8018 \mathrm{kgF}$. [9]

\subsubsection{The centrifugal tension, $P_{c}$}

$$
P_{c}=W V^{2} / g
$$


Where $g=$ acceleration due to gravitational pull $=$ $9.81 \mathrm{~m} / \mathrm{s}^{2}$

$$
\begin{gathered}
V=\text { chain velocity }(\mathrm{m} / \mathrm{s})=\frac{d_{1} n_{1}}{60} \\
V=\frac{0.08311 \times 132}{60}=0.5746 \mathrm{~m} / \mathrm{s} . \\
P_{c}=\frac{0.77 \times 0.5746^{2}}{9.81}=0.0259 \mathrm{kgF}
\end{gathered}
$$

The tangential force due to power transmission $P_{t}$

$$
P_{t}=\frac{102 N}{V}
$$

Where

$N=$ power transmitted on the basis of breaking load

$$
N=\frac{Q V}{102 n K_{S}}
$$

Where

$$
\begin{aligned}
& Q=\text { breaking load }=1730 \mathrm{kgF} \\
& d_{1}=\text { diameter of small sprocket }=0.83109 \mathrm{~m} \\
& V=\text { chain velocity }(\mathrm{m} / \mathrm{s})=0.5746 \mathrm{~m} / \mathrm{s} \\
& n=\text { factor of safety }=7.8 \\
& K_{S}=\text { service factor }=2.34375 \\
& N=\frac{1730 \times 0.5746}{102 \times 7.8 \times 2.34375}=0.5331 \mathrm{~kW}
\end{aligned}
$$

Hence, $P_{t}=\frac{102 \times 0.5331}{0.5146}=105.667 \mathrm{kgF}$

$P=P_{t}+P_{c}+P_{s}=1.8018+0.0259+105.667=$

$107.4947 \mathrm{kgF}$

$P=107.4947 \times 9.81=1054.52 \mathrm{~N}$

Hence the actual factor of safety $(\eta)$

$$
\eta=\frac{Q}{P}=\frac{1730}{1054.52}=1.64
$$

\subsubsection{Determination of the required torque to rotate the load-carrying shaft}

Safe speed of the rotating basket to ensure $90 \%$ efficiency and to preserve the comb from damaging is between 180 to $320 \mathrm{rpm}$

Therefore, the required selected speed of shaft, $V_{s}=250 \mathrm{rpm}$

Mass of shaft (without load), $m_{s}=1.8 \mathrm{~kg}$ Mass of basket (without load), $m_{b k}=6.2 \mathrm{~kg}$ Mass of bearing, $m_{b}=0.2 \mathrm{~kg}$ Mass of one (1) honey comb + frame, $m_{h}=$ $1.1 \mathrm{~kg}$
Mass of one (6) honey comb + frame $=6.6 \mathrm{~kg}$

Mass of shaft (with load), $m=m_{s}+m_{b k}+m_{b}+$ $m_{h}$

$$
m=1.8+6.2+0.2+6.6=14.8 \mathrm{~kg}
$$

To calculate the torque of the rotating basket

$$
T=I \alpha
$$

Where $T=$ Torque of the basket

$$
I=\text { moment of inertia of the basket }
$$$$
\alpha=\text { angular acceleration of the basket }
$$

To determine the moment of inertia of the basket,

$$
I=\frac{1}{2} m r^{2}
$$

Where $\mathrm{m}=$ mass of loaded shaft $=14.8 \mathrm{~kg}$

$r=$ radius of the basket from the centre $=0.33 \mathrm{~m}$

$$
I=\frac{1}{2} \times 14.8 \times(0.33)^{2}=0.8059 \mathrm{~kg} / \mathrm{m}^{2}
$$

To determine $\alpha$,

Angular velocity of the basket, $\omega=\frac{2 \pi \mathrm{V}}{60}=$ $\frac{2 \pi \times 250}{60}=26.19 \mathrm{rad} / \mathrm{s}$

$\alpha=\omega^{2} r=26.19^{2} \times 0.33=226.35 \mathrm{rad} / \mathrm{s}^{2}$

Hence the torque $T=0.8059 \times 226.35=$ $182.42 \mathrm{Nm}$

\subsubsection{Determination of the required power to} drive the rotary basket

$$
P=\frac{2 \pi T V}{60}
$$

Where $P=$ Power

$$
\begin{aligned}
& T=\text { Torque }=182.42 \mathrm{Nm} \\
& V=\text { Speed in } \mathrm{rpm}=250 \mathrm{rpm} \\
& P=\frac{2 \pi \times 182.42 \times 250}{60}=4777.99 \mathrm{Watts} \\
& P=4.78 \mathrm{~kW}[10]
\end{aligned}
$$

To determine the $\mathrm{V}$-belt design power, $\mathrm{P}^{\prime}$

$$
\mathrm{P}^{\prime}=\mathrm{SF} \times \mathrm{P}
$$

$S F=$ Service factor

$=1.1$ (for centrifugal machine performing intermittent service)

$\mathrm{P}=$ Required power $=4.78 \mathrm{~kW}$ 
$\mathrm{P}^{\prime}=1.1 \times 4.78=5.26 \mathrm{~kW}$

The following known parameters were used in the determination of the speed ratio

Design Power, $\mathrm{P}=5.26 \mathrm{~kW}$

Driven pulley rotational speed, $n_{p 2}=250 \mathrm{rpm}$

Driver pulley rotational speed, $n_{p 1}=132 \mathrm{rpm}$

Distance between axes of pulley,

$A=480$ (pre - selected $)$

Acceptance error for belt drive ratio, $\Delta=3 \%$

\subsubsection{Limitation of the belt drive ratio, i}

$$
\begin{aligned}
& \mathrm{i}=\frac{n_{p 2}}{n_{p 1}} \\
& =\frac{250}{132}=1.89 \\
& \mathrm{i}_{\max }=\mathrm{i} \times\left[1+\frac{\Delta}{2.1}\right] \\
& \mathrm{i}_{\max }=1.89 \times\left[1+\frac{0.03}{2.1}\right]=1.917 \\
& \mathrm{i}_{\min }=\mathrm{i} \times\left[1-\frac{\Delta}{2.1}\right] \\
& \mathrm{i}_{\min }=\mathrm{i} \times\left[1-\frac{0.03}{2.1}\right]=1.863
\end{aligned}
$$

The diameter chosen for the driver pulley, $D_{1}=125 \mathrm{~mm}$

The diameter chosen for the driven pulley, $D_{2}=250 \mathrm{~mm}$

$$
\text { The real drive ratio, } \begin{aligned}
\mathrm{i}_{\text {real }} & =\frac{D_{2}}{D_{1}} \\
& =\frac{250}{125}=2
\end{aligned}
$$

The belt drive ratio $\mathrm{i}_{\text {real }}=2$ is acceptable [11]

\subsubsection{Selection of a length of the belt}

Angle of slope, $\mathrm{y}$ of the belt is calculated as

$$
\begin{aligned}
\operatorname{Sin} \mathrm{Y} & =\frac{\mathrm{D}_{2}-\mathrm{D}_{1}}{2 \mathrm{~A}} \\
& =\frac{250-125}{2(480)}=0.1302 \\
\mathrm{Y} & =\sin ^{-1}(0.1302)=7.48^{0}
\end{aligned}
$$

\subsubsection{Length of the belt}

$$
\begin{aligned}
& L=\pi\left[\frac{D_{1}+D_{2}}{2}\right]+\pi\left[\frac{\gamma}{180}\right]\left[D_{2}-D_{1}\right]+2 A \operatorname{Cos} \gamma \\
& L=3.143\left[\frac{125+250}{2}\right]+3.143\left[\frac{7.48}{180}\right][250-125]+ \\
& 2[480 \operatorname{Cos} 7.48]=1557 \mathrm{~mm}
\end{aligned}
$$

Therefore, a length $L=1600 \mathrm{~mm}$ was chosen [12]

In calculating the belt speed $\mathrm{V}(\mathrm{m} / \mathrm{s})$

$$
\begin{aligned}
& V=\frac{D_{1} n_{1}}{60 \times 10^{3}} \\
& V=\frac{125 \times 132}{60 \times 10^{3}}=0.8639 \mathrm{~m} / \mathrm{s}
\end{aligned}
$$

\subsubsection{Determination of the force required to drive the shaft and basket}

The calories required for riding a bicycle is 175 $\mathrm{cal} / \mathrm{hr}$

$$
\begin{aligned}
& \text { Therefore if } 1 \mathrm{cal}=4.184 \mathrm{~J} \\
& 175 \mathrm{cal}=(175 \times 4.184) \mathrm{J} \\
& 175 \mathrm{cal}=732.2 \mathrm{~J} / \mathrm{hr} \\
& \text { But } \text { Power }=\frac{\text { work }}{\text { time }}(\mathrm{J} / \mathrm{sec}) \\
& \text { Power }=\frac{732.2}{3600} \mathrm{~J} / \mathrm{sec}=0.2034 \mathrm{~J} / \mathrm{sec}
\end{aligned}
$$

Also Power $(P)=$ Force $(F) \times \operatorname{Velocity}(V)$

$$
\begin{aligned}
& P=F \times V \\
& F=\frac{P}{V} \\
& F=\frac{0.2034}{0.577}=0.3525 \mathrm{~N}
\end{aligned}
$$

\subsubsection{Engineering drawings for production}

The isometric drawing of this machine is as shown in Fig. 1. The orthographic views as well as the exploded drawing and other drawings of the component parts are as shown in Figs. 2, $3,4,5,6$ and 7 .

\subsection{Production Cost}

The table below shows the cost estimates involved in the production of the honey extractor.

Table 1. Production cost

\begin{tabular}{lll}
\hline & $\#$ & USD $\$$ \\
\hline i. Bought-out component cost & 10150 & 50.75 \\
ii. Material cost & 27000 & 135 \\
iii.Machining cost & 6100 & 30.5 \\
iv. Non-machining cost & 5500 & 27.5 \\
Total Estimated cost & 48750 & 243.75 \\
\hline
\end{tabular}

\subsection{Performance Evaluation of the Machine}

The design of the honey extracting machine was targeted towards obtaining $250 \mathrm{rpm}$ speed of the 
revolving honey frame (rotary basket). At the end of the construction, the maximum speed attainable was $270 \mathrm{rpm}$. During the test of the efficiency of the machines, these were the results gathered. However, it is important to note that the frame rotary basket was reloaded with new honey combs at each working operation.
Since efficiency is known to be the ratio of output to input, the formula for the production efficiency was derived and efficiency $(\varepsilon)$ by calculation was

$$
\begin{aligned}
\varepsilon & =\frac{\text { mass of extracted honey }}{\text { mass of honey comb processed }} \times 100 \% \\
& =\frac{5.61}{6.60} \times 100 \%=85 \%
\end{aligned}
$$

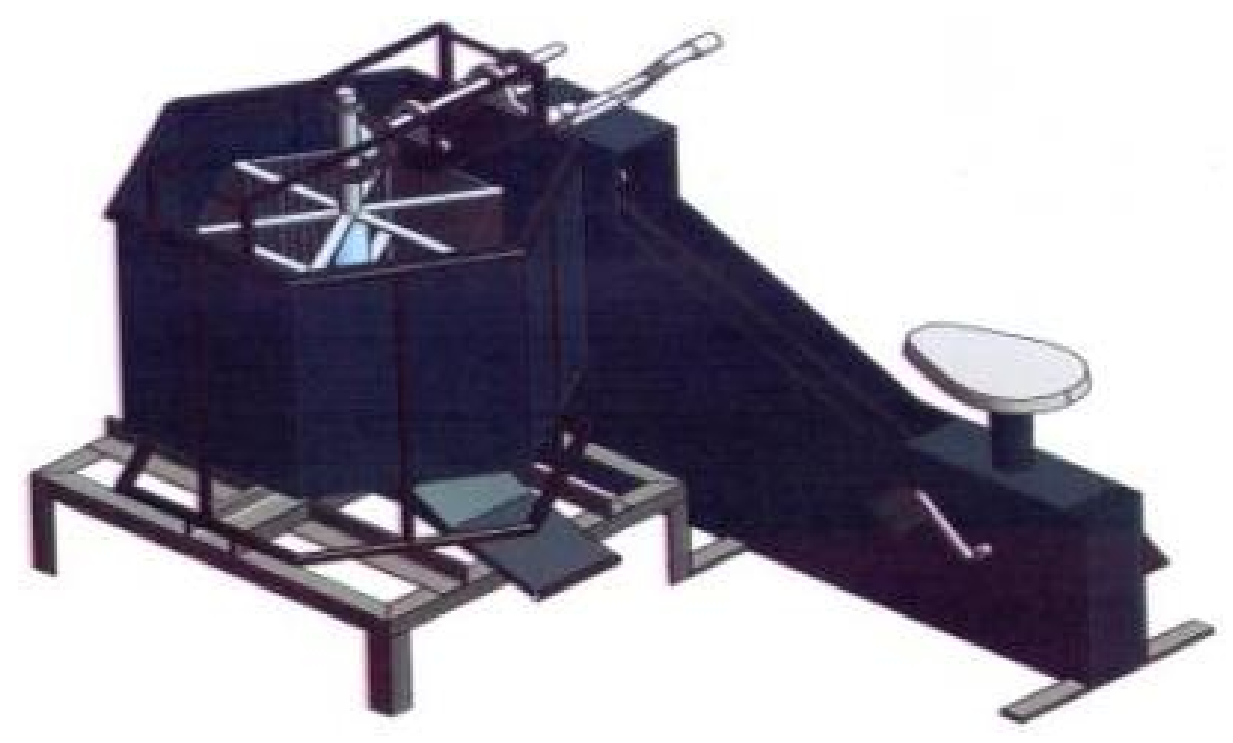

Fig. 1. Isometric view of the honey extractor
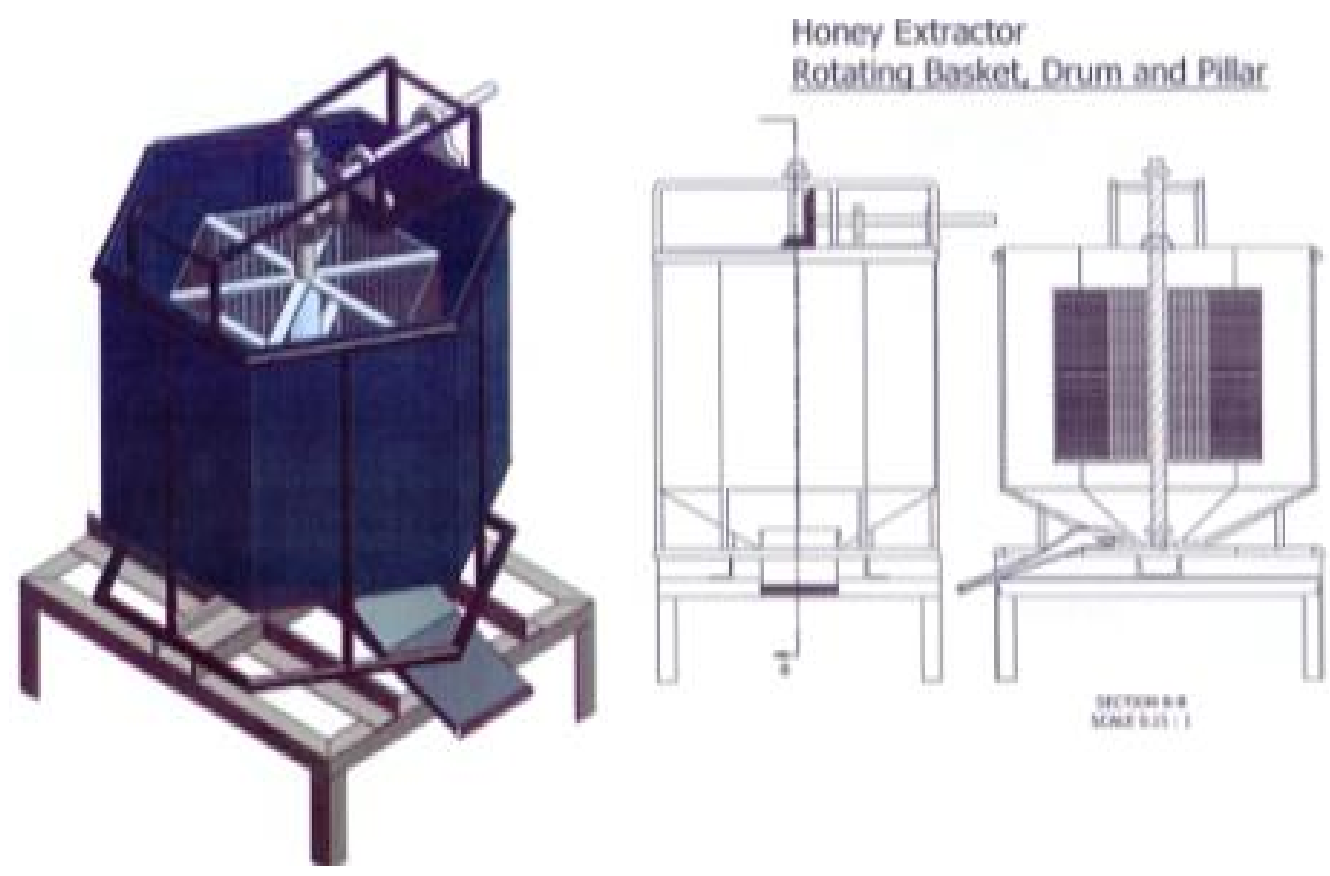

Fig. 2. Conceptual and frame diagrams for the honey extractor drum with basket 
Table 2. Performance evaluation for the machine

\begin{tabular}{llllll}
\hline S/No & Parameter & $\begin{array}{l}\text { First } \\
\text { working } \\
\text { condition }\end{array}$ & $\begin{array}{l}\text { Second } \\
\text { working } \\
\text { condition }\end{array}$ & $\begin{array}{l}\text { Third } \\
\text { working } \\
\text { condition }\end{array}$ & Average \\
\hline 1 & Density of honey $\left(\mathrm{kg} / \mathrm{m}^{3}\right)$ & 1402.7 & 1402.7 & 1402.7 & 1402.7 \\
2 & Total mass of honey frame $(\mathrm{kg})$ & 6.6 & 6.6 & 6.6 & 6.6 \\
3 & Speed of the frame basket $(\mathrm{rpm})$ & 250 & 260 & 270 & 260 \\
4 & Time taken for operation $(\mathrm{min})$ & 20 & 20 & 15 & 18.3 \\
5 & Volume of honey extracted $\left(\mathrm{m}^{3}\right)$ & 0.004 & 0.004 & 0.004 & 0.004 \\
6 & Mass of honey extracted $(\mathrm{kg})$ & 5.61 & 5.61 & 5.61 & 5.61 \\
\hline
\end{tabular}
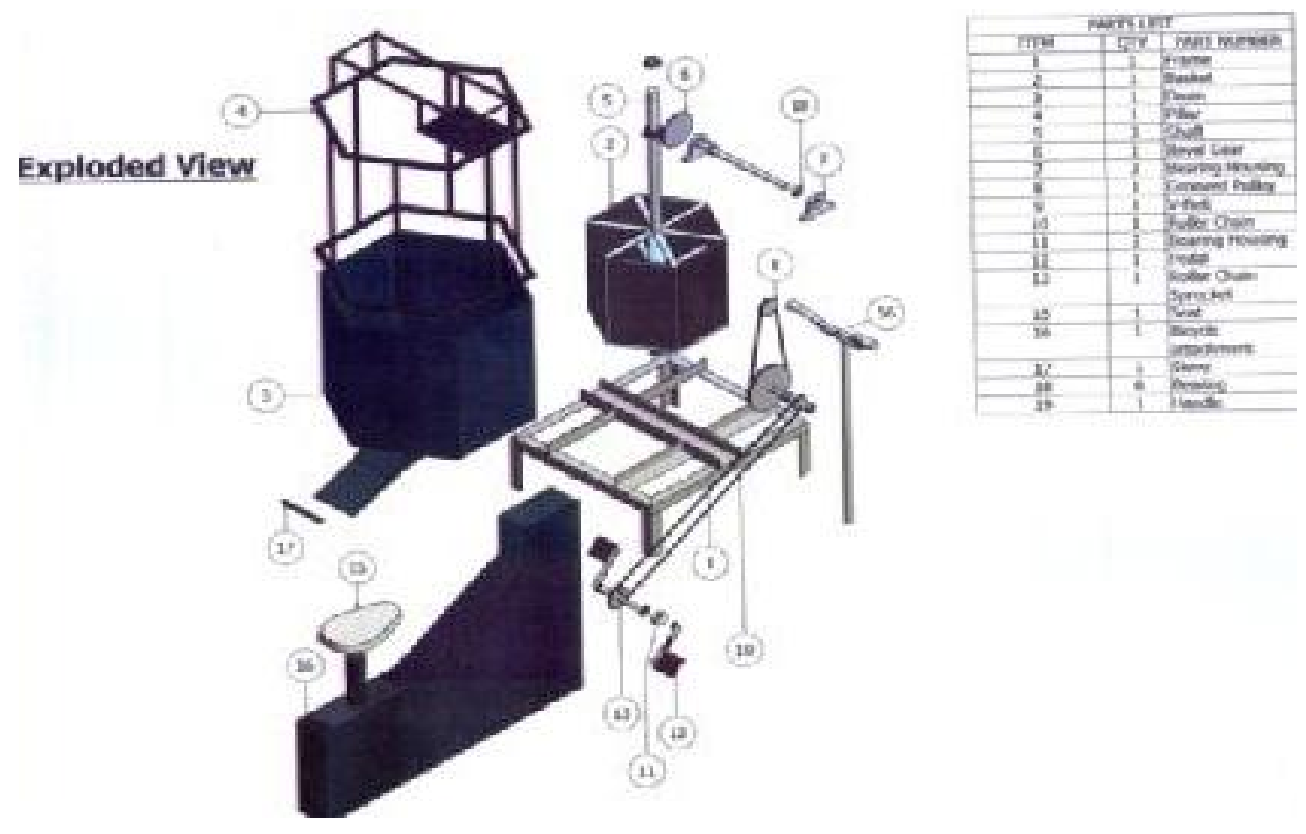

Fig. 3. Exploded view of the honey extractor
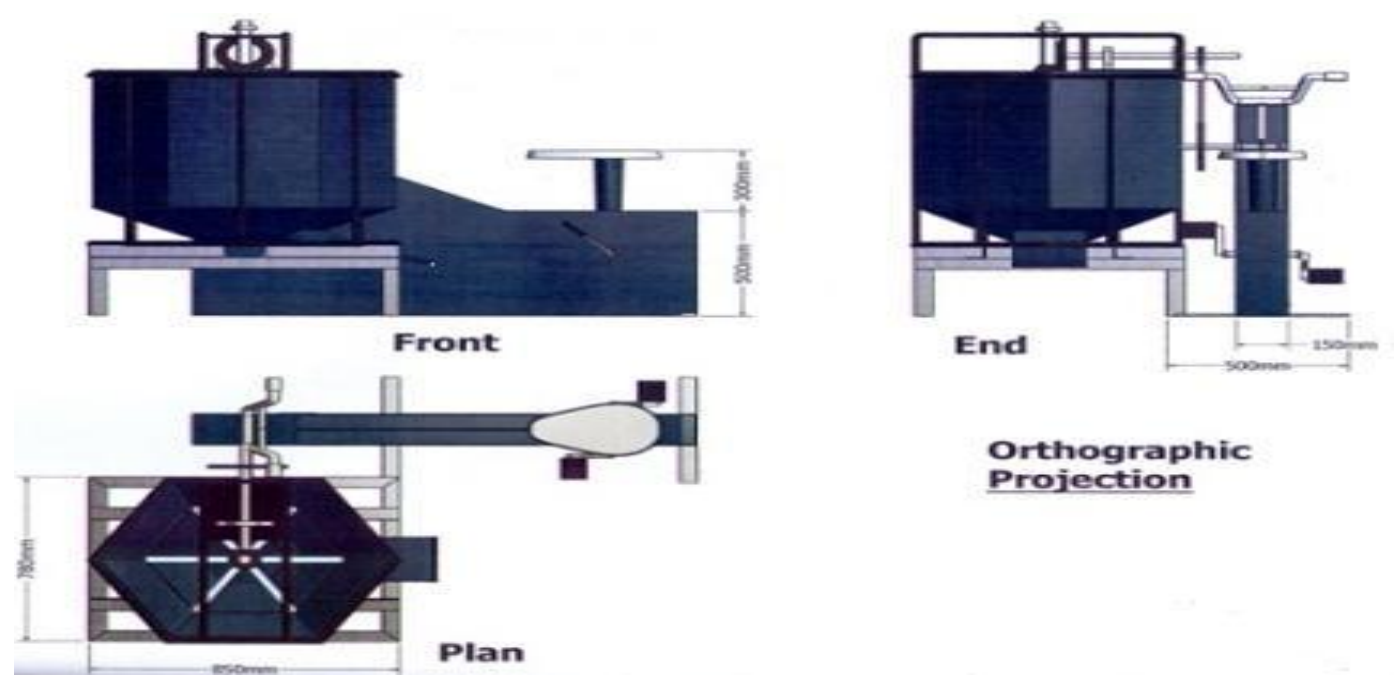

Orthographic Projection

Fig. 4. Orthographic projection of the honey extractor 


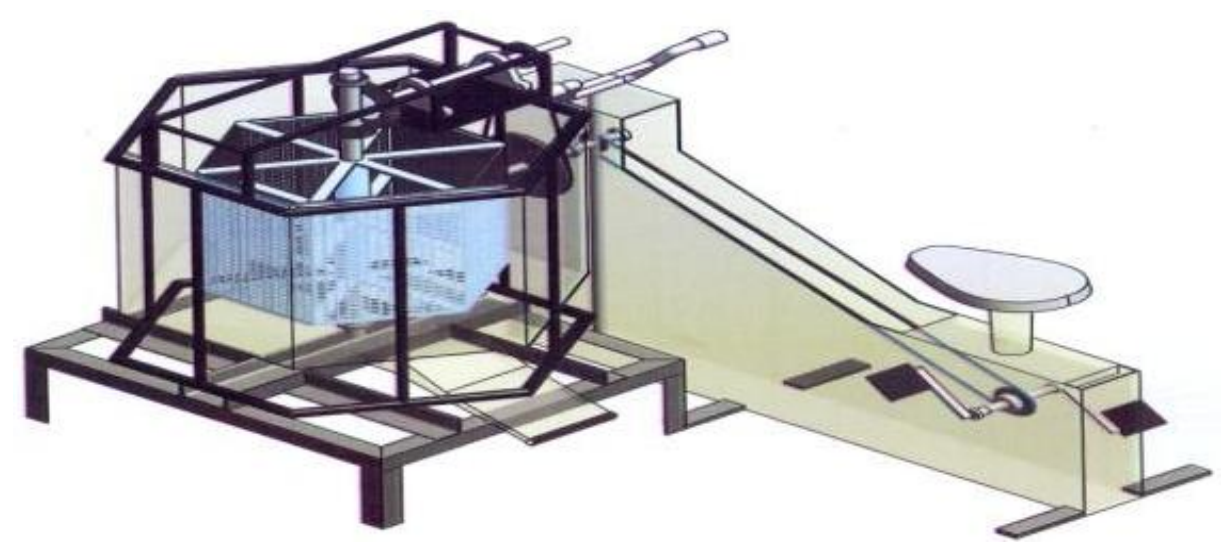

Fig. 5. Isometric conceptual diagram for the honey extractor

\section{RESULTS AND DISCUSSION}

Table 2 shows the average volume of the honey, average mass of honey, average speed of the rotating basket, average time taken for the operation to be $0.004 \mathrm{~m}^{3}, 5.61 \mathrm{~kg}, 260 \mathrm{rpm}$ and $18.3 \mathrm{~min}$ respectively.

When average mass of $6.6 \mathrm{~kg}$ honey comb was fed into the spinning metal basket, the hand driven type averagely produced $5.50 \mathrm{~kg}$ of honey while the pedal type produced $5.61 \mathrm{~kg}$ of honey. Hence, the production efficiency of this design was $85 \%$ as compared to the design of $[5,6]$. The efficiency of their designs were $81.8 \%$ and $83.29 \%$ respectively. This is a slight improvement to existing designs. Although, the previous design was an extractor locally made for indigenous honey keepers which was hand driven was effective to some extent; however; in terms of production en mass, the hand driven extractor is not very effective because it can cause occupational health disorder to its user due to repetitive cycling of the hand driver of the extractor. The pedal driven extractor uses a mechanism that helps gather easy momentum to drive the extractor within a short period unlike the hand driven type; hence reducing occupational health disorder encountered in the former design. The modification made on the machine was the changing of the hand driven mechanism to the pedal driven mechanism. From the Table 1, the production cost for the entire machine was estimated to be \#48750 (\$243.75).

\section{CONCLUSION}

Hand driven honey extractor formerly designed was redesigned so that it could accommodate a pedal mechanism instead of being driven by hand. It was an improved design on the former design because the effectiveness of the former design was $83.29 \%$ and that of this new design was $85 \%$; in which the new one was found to be more efficient. Also the shortcomings as observed in the previous design were overcome in this new design in that the operator that easily get tired after a few repetition in driving the extractor can now spin repeatedly as many times as possible without being tired. This is an increase to productivity of the system and can be employed in mass production of honey. The honey extractor is an effective and hygienic means of extracting honey from the honey comb. Although the design might be quite expensive, it met the desired requirement of hygienic food handling and it is maintenance friendly, in that all the parts are replaceable when the need arises. The users of this machine will find it interesting to operate. It can be operated by anyone who has the little energy required to drive the pedals.

\section{ACKNOWLEDGEMENT}

The authors wished to appreciate Mr. Fasan of the workshop of FUTA for his unrelented effort to see to the actualization of the fabrication and testing of this machine. Also, we appreciated the department of Mechanical Engineering, FUTA for their support.

\section{COMPETING INTERESTS}

Authors have declared that no competing interests exist.

\section{REFERENCES}

1. Michael OF. Costs and returns in modern beekeeping for honey production in 
Nigeria. Pakistan Journal of Social Sciences. 2008;5(4):310-15.

2. Vallianou NG, Gounari P, Skourtis A, Panagos J Kazazis C. Honey and its antiinflammatory, antibacterial and anti-oxidant properties. Gen Med (Los Angel). 2014; 2(132):1-5.

3. Sampath KP, Debjit B, Chiranjib Biswajit, Chandira MR. Medicinal uses and health benefits of honey: An Overview. Journal of Chemical Pharmaceutical Research. 2010; 2(1):385-95.

4. Akinnuli BO, Abadariki SO, Fasan JO. Design, fabrication and performance evaluation of an indigeneous honey extractor. J. of Emerging Trends in Engineering and Applied Sciences (JETEAS). 2013;4(1):1-6.

5. Afogba M. Design and construction of honey extractor. Federal University of Technology, Akure student's project. 2005; 1-63. (Unpublished B.Eng. project).
6. Abioye O. Modification, construction and testing of honey extracting machine. Federal University of Technology, Akure student's project. 2006;1-65. (Unpublished B.Eng project).

7. Gopinath K, Mayuram M. Spur gear design. Indian Institute of Technology, Madras.

8. Maleev V, James B. Machine design. 3rd ed. CBS Publisher and Distributors; 1983.

9. Sharma C, Purohit K. Design of machine elements. 2nd ed. Prentice Hall of India: New Delhi; 2003.

10. Tyler $\mathrm{GH}$. Handbook of mechanical engineering calculations: Shafts. Flywheels, Pulleys and Belts for Power Transmission, 2nd ed; 2006.

11. Shigley JE, Mischke CR. Mechanical engineering design. 5th ed. McGraw Hill Publication; 2000.

12. Spotts MF. Design of machine elements. 6th ed. Prentice Hall India Pvt. Limited; 1991.

(c) 2016 Akinnuli et al.; This is an Open Access article distributed under the terms of the Creative Commons Attribution License (http://creativecommons.org/licenses/by/4.0), which permits unrestricted use, distribution, and reproduction in any medium, provided the original work is properly cited.

Peer-review history:

The peer review history for this paper can be accessed here: http://sciencedomain.org/review-history/14641 